\title{
Applied Research on Leadership in Community Colleges
}

\author{
ROBERT A. HALL \\ RICHARD L. ALFRED
}

A good working definition of "leadership" is provided by Hersey and Blanchard (1977): "Leadership is the process of influencing the activities of an individual or a group in efforts toward goal achievement in a given situation." Leadership, therefore, requires the presence of two or more persons, some objective to be attained, and some operational situation under which the various factors at work come together. It does not imply quality in any absolute sense; rather it implies an appropriate matching of the personal characteristics of the leader with the nature of the situation as perceived by both the leader and those being led.

This paper presents a synthesis of a recent study of leadership in community college. The objective of the study was to examine interactive leadership relationships between community college presidents and the principal internal governance groups with which they must work-their boards of trustees and their administrative cabinets. Beginning with the premise that boards and administrative cabinets offer presidents differing leadership situations resulting from different responsibilities, structural relationships, backgrounds and needs, the paper first presents a model for analysis of presidential leadership style with identified campus constituencies. Results obtained through research administration of the model at seven community college campuses in Fall 1982 are then described and summary observations are drawn. The paper concludes with a statement of the implications of current president/board relationships for future community college leaders given the reality of changing external conditions and resource levels.

\section{Model for Analysis of Leadership}

Whether a president is able to deal with differing leadership situations in an equally effective manner, given his/her individual leadership style, may determine the amount of satisfaction that is gained from the chief executive officer position. It may also determine the degree of management stability that will be present in a particular college. 
A Contingency Model of Leadership Effectiveness can be used to examine relationships between presidents and their boards of trustees and administrative cabinets. Diagrammed in Figure 1, this model gauges the level of leadership effectiveness by comparing the leadership style of the president with important characteristics of the group situation in which interaction between leaders and group members takes place. Developed by Frederick Fieldler in 1976, contingency theory holds that "leadership style" is a relatively fixed personal characteristic. The "group situation"- a concept comprised of factors such as characteristics of leader-member relations, task structure, and position power of the leader relative to the group-is subject to considerable change through the alteration of one or more of its characteristics. The concept underlying the Contingency Model is that the success of the leader is highly dependent upon the "match" of his/her leadership style and the situation presented by the group or groups that the leader seeks to lead. Thus, the Contingency Model has two principal interacting variables: leadership style and leadership situation.

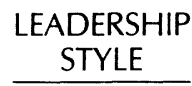

President

President $\rightarrow \quad \begin{gathered}\text { Administrative } \\ \text { Cabinet }\end{gathered}$

GROUP

SITUATION

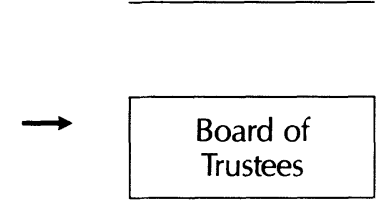

Leader/Member

Relations

Task Structure

Position Power

of President

$\downarrow$

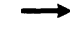

Unstructured Tasks

Strong Position Power

of President

Positive Leader/Member Relations
Positive Leader/Member Relations

Structured Tasks

Strong Position Power of President

FIGURE 1

\section{Contingency Model of Leadership Effectiveness}


Utilizing idealized relationships between leadership style and leadership situation, a research portfolio consisting of an interview protocol for community college presidents, a mailed survey instrument for members of boards of trustees, and a mailed survey instrument for administrative cabinet members was administered to seven community colleges in a midwestern state. Organizationally, the participating colleges were similar. Each has a president and a seven-member elected board of trustees. Each had an adminstrative cabinet, whose size was dependent upon the needsof the president. The sevenparticipating cabinets ranged in size from four to twelve member. Student enrollment in the participating colleges ranged from 1,300 to 15,000 full-time-equivalent students. The geographic location of the colleges was small-city or large-city suburban. Two of the seven colleges were multi-campus in structure.

In addition to demographic features, the colleges were chosen for a number of other reasons. Two had presidents who were founding presidents, having served more than 15 years in office. One college had a president with only one year of service. Another college had a president who had been president of two colleges in the state system. Finally, some of the colleges had reputations for harmonious president/board relationships, while others had reputations for disruptive relationships.

The interview protocol and survey instruments yielded a considerable amount of information about presidential leadership style in each college. The analysis of the data required a blending of self-reported information and published statistical information about each college. Because all of the data concerned perceptions in which there were no fixed data points, care had to be taken to establish base points by which a judgment could be made as to whether a particular relationship between a president and board of trustees or a president and administrative cabinet was unusual or typical. For example, a continuum of relationships was possible between the president and board and president and administrative cabinet at each college ranging from "positive" (depicting a close match between presidential leadership style and group situation) to "negative" (depicting a leadership style highly inappropriate to the group situation). The task was to identify and locate relationships between presidents and internal governance groups on specific points of the continuum for a particular college.

Case studies were prepared for each college. After all the individual cases were completed, a summation was prepared thereby putting each leader-group situation into necessary perspective. The case analyses were then modified to include central tendency data and to draw preliminary conclusions from the perspective of all colleges in the study. Using this approach, conclusions and implications were drawn concerning the relationship of presidents to internal constituencies with decision-making authority in community colleges.

\section{Presidential Relationships with Boards and Administrative Cabinets}

Community college trustees and administrative cabinet members perceived presidents as falling on a scale between high human relations orientation and high task/job orientation, with most being moderately task oriented in terms of leadership style. Both groups seemed to prefer that presidents become somewhat more oriented toward a task-oriented leadership style, providing that they did not shift to extreme behavior. Cabinets perceived presidents as tending more toward human 
relations behavior than did board members. Cabinet members, however, expressed an even stronger preference for task-oriented behavior than did board members. Both board and cabinet members tended to associate effectiveness in presidents with a task-oriented style.

Concerning the group leadership situation, the current research indicated that the group situation inherent in boards of trustees depended must upon whether leader/member relations were positive or negative. The majority of boards (four of seven) reflected a group leadership situation in which leader/member relations were positive, tasks were unstructured, and the leader position power of the president was strong, indicating a moderately favorable roup situation. The colleges with an unfavorable presidentboard leadership situation appeared to have particularly poor leader/member relations.

A somewhat different leadership group situation was identified for administrative cabinets. The majority of president/cabinet relationships were found to be characterized by good leader/member relations, structured tasks, and strong leader position power, indicating a highly favorable group situation. Cabinet group leadership situations were found to be more favorable to the presidents than were board group leadership situations. In no college were both board and cabinet group situations found to be unfavorable to the president.

Having closely studied group/leadership situations in a number of community colleges, specific observations can be made about president/board and president/ cabinet relationships:

(1) Boards and cabinets appear to prefer presidents who are evely oriented between human relations and task-oriented style or who tend to favor a moderately task-oriented style.

(2) Administrative cabinets display a greater dissatisfaction with, and a desire for, leadership style changes among presidents than do boards. Both boards and cabinets prefer presidents to concentrate on the task rather than seeking to improve their human relations. Presidents frequently appear to equate improving their effectiveness with groups with improving their human relations skills. Board and cabinet members place greater emphasis on task accomplishment than upon any desire for having presidents consciously improve their human relationships with each group. Leader/member relations appear to be determined more by successful task accomplishment than by personality skills.

(3) Community college presidents exhibit moderate leadership styles, which allow them the capability of adjusting their behavior to meet the changing needs and desires of boards and administrative cabinets. More radical styles on the part of presidents might ideally suit a particular emerging situation, but might result in severe mismatches of style and situation as group situations almost inevitably change. Extreme leadership styles appear to discourage long tenure and institutional stability.

(4) Task structure offers the greatest opportunity for situational adjustment on the part of either a group or the president. Ambiguities in group tasks lead to misunderstandings and to the deterioration of leader/member relations within both boards and administrative cabinets. Task-oriented presidents tend to complement groups which require structured procedures and objective accomplishments. Human-relations-oriented leaders tend to function better with groups which are more general in their approach to responsibilities. Efforts to improve communications within the group and to increase 
knowledge about community needs, institutional priorities, and organizational realities can provide group members with a better basis for understanding group tasks.

(5) Leader satisfaction is generally understated as it relates to effectiveness. This results in presidents being more concerned about their standing with the board and the administrative cabinet than conditions would seem to warrant. Boards, and to a lesser extent cabinets, need to be aware that presidents lead relatively lonely lives which require a modicum of ego incentives to raise satisfaction commensurate with responsibilities of the position.

(6) Group leadership situations are rarely static, changing more from shifts in group membership than from changes in institutional conditions. Unless presidents recognize and deal with changes in the group leadership situation, changes in leaders will almost inevitably occur. Group training and socialization is almost always required to stabilize the group leadership situation and to improve the ability of groups to relate to their leaders.

\section{Implications for Tomorrow's Leaders}

Leadership experience, in itself, will not be a guarantor or presidential effectiveness in tomorrow's community colleges. Similarly, a change of leadership will not be a panacea for solving institutional problems. Presidents whose leadership styles no longer fit the realities of the group leadership situation with boards and administrative cabinets will have very little opportunity to continue in their positions. These observations are of limited, value, however, unless they can be translated into an answer to the question: What characteristics or management skills should presidents have to provide leadership for community colleges in the decade ahead?

The current study indicates that presidents whose styles are evenly or moderately divided between a human relations orientation and a task orientation are capable of necessary marginal adjustments in leadership style. Presidents who have had a long tenure in the job appear to be well served by two characteristics; first, the ability and willingness to make marginal changes in their leadership style and second, the ability and the stature necessary to adjust the group organization or group leadership situation to satisfy changing institutional conditions. Left unanswered is the question of whether "marginal adjustments" in leadership style will be sufficient to provide leadership for community colleges facing serious programmatic, finance, and governance issues in the future. Moderate leadership styles may culminate in long tenure, but they may not produce satisfactory responses on the part of the institution to challenging conditions in the external environment. It is entirely possible that radical, risk-taking leadership styles will be needed in the future to advance two-year colleges forward in debates about mission definition, program-service mix, clientele, governance, access, and cost. Such leadership styles may fly directly in the face of boards and cabinets that desire stability, presidents may become the subject of mounting criticism from internal constituencies, and turnover in the presidency may become more frequent, but the institution may continue on a development course in the difficult period ahead.

Community college presidents cannot afford to "play it too safe" with boards of trustees and administrative cabinets. Strategies will need to be developed and risks will need to be taken in decisions about the future of the institution. In the future, boards and administrative cabinets will need to be socialized into acceptance of a 
risk-taking leadership style at least on a situational basis. Leaders will not be able to engage in careless and capricious decision making about institutional priorities. Information produced through automated data systems and painstaking research will become a critical ingredient in the decision process with boards and cabinets. Compliance and voluntary support on the part of board and cabinet members will be necessary if leaders are to process, synthesize, and convert this information into good decisions.

Presidents with effective leadership skills in tomorrow's colleges can best be described as possessing hybrid qualities. They will have the capacity to take risks when necessary, but also to maintain stability in internal management through modification of extreme leadership styles to fit changing situations. They will be able to provide leadership for boards and administrative cabinets in identifying institutional priorities, but they will also be able to compromise when group conditions mandate consensus rather than divisiveness. Finally, tomorrow's leaders will have an acute sense of timing. They will know when to make adjustments in the internal sturcture to meet changing external conditions, when to push the institution forward through high-risk decisions, and when to pull back and let situations emerge.

\section{References}

Blake, R. R. \& Mouton, J.S. (1964). The Management Grid. Houston, Texas: Gulf Publishing Company.

Blanchard, K. H. (1967). The favorable of the group situation in a board of trustees to its principal designated leaders-the college president and the board chairman. Unpublished doctoral dissertation, Cornell University.

Fiedler, F. E. (1967). A Theory of Leadership Effectiveness. New York: McGraw-Hill.

Gibson, J. L., Ivancevich, J. M., \& Donnelly, J.H., Jr. (1979). Organization, Behavior, Structure, Processes. Dallas, Texas: Business Publications, Inc.

Hall, R. A. (1983). Presidential leadership styles relevant to the group situations in community college boards of trustees and administrative cabinets. Unpublished doctoral dissertation, University of Michigan.

Hersey, P. \& Blanchard, K. H. (1977). Management of Organizational Behavior, 3rd Edition. Englewood Cliffs, N. J.: Prentice-Hall, Inc.

Stodgill, R. M. \& Coons, A. E. (1957). Leader Behavior: Its Description and Measurement. Columbus, Ohio: The Ohio State University.

Robert A. Hall is Director of Continuing Education, Naval War College, Newport, Rhode Island.

Richard L. Alfred is Associate Professor of Higher Education and Director of the Community College Program, University of Michigan, Ann Arbor, Michigan. 